\title{
INTRODUCING NANOTECHNOLOGY THROUGH UNDERGRADUATE THERMAL-FLUID RESEARCH PROJECTS
}

\author{
ROY J. ISSA \\ West Texas A\&M University, USA
}

\begin{abstract}
Nanotechnology research has recently been introduced in the mechanical engineering program at West Texas A\&M University through undergraduate thermal-fluid science projects. The projects were offered at the junior and senior level in the program as part of either an independent research course or thermal-fluid design course. The projects have been carefully selected to provide the students with an exposure to nanotechnology concepts through experimental studies. Several of those projects were design-oriented in their focus. This paper addresses four of those projects: 1) design of a closed-loop electronics cooling system using nanofluids; 2) performance evaluation of a radiator-type automobile heat exchanger using a circulating nanofluid; 3) evaluation of the energy absorption by alumina nanoparticles in solar vacuumed tubes; and 4) design of a cost effective filter for water purification in developing countries using clay material impregnated with silver nanoparticles for anti-microbial protection capability. The first two projects investigated the effect of using alumina water-based nanofluid compared to distilled water in enhancing the heat transfer performance of the systems. Parametric studies were conducted to investigate the effect flow operating conditions, nanoparticle size and concentration have on the heat exchanger effectiveness. The third project investigated the effect alumina nanoparticles have on the heat gained by an alumina water-based nanofluid in a solar vacuumed tube. In the fourth project, a clay filter was designed for optimal permeability, porosity, filter thickness, daily flow rate, and silver nanoparticles concentration in the clay. An investigation of the effectiveness of the filter was conducted by analyzing certain parameters such as the water turbidity level and presence of bacteria and in the filtered water.
\end{abstract}

Keywords: nanoparticles, nanofluid, nanotechnology, heat transfer.

\section{INTRODUCTION}

Nanoparticles have found their use in many thermal-fluid application areas due to the improvement they make at the extremely small scale. When nanoparticles are suspended in a base fluid, the resulting fluid referred to as a nanofluid exhibits significant enhancement in thermophysical properties such as thermal conductivity, thermal diffusivity, viscosity and convective heat transfer coefficients compared to the base fluid [1], [2]. Some of the areas where nanofluids are used include the automotive, electronic, biomedical, lubrication, oil recovery, and detergency [3].

The benefit of using nanofluids in heat exchangers have been investigated by several researchers. Selvakumar and Suresh [4] studied the performance of $\mathrm{CuO}$ water-based nanofluid in an electronic heat sink. Their study revealed a 29\% improvement in heat transfer coefficient for $0.2 \%$ volume fraction of $\mathrm{CuO}$ in deionized water. Khedkar et al. [5] studied the heat transfer in a concentric tube heat exchanger with different volume fractions of waterbased $\mathrm{Al}_{2} \mathrm{O}_{3}$ nanofluids. It was observed that at a $3 \%$ optimal volume fraction of alumina, the overall heat transfer coefficient was about $16 \%$ higher than that of water.

Nanofluids were recently used in solar distillation. Performance analysis using different concentrations of gold nanoparticles in solar tubes was conducted by Jin et al. [6]. It was shown that under a solar concentration of 220 Suns and gold nanoparticles concentration of $1.02 \mathrm{ppm}$, a specific absorption rate of $52 \mathrm{~kW} / \mathrm{g}$ can be achieved. Mittelman et al. [7] studied 
the effect of $\mathrm{Al}_{2} \mathrm{O}_{3}$ nanoparticles on the performance of passive double slope solar still. It was shown that for a $0.12 \%$ concentration of $\mathrm{Al}_{2} \mathrm{O}_{3}$ nanoparticles, the enhancement in the yield rate for a 35 and $80 \mathrm{~kg}$ base fluid was $12.2 \%$ and $8.4 \%$ respectively compared to the base fluid.

The use of nanoparticles such as silver has been implemented in the purification of water due to the solver antimicrobial benefits. Studies show the release of silver ions $\mathrm{Ag}^{+}$into contaminated water can produce free radicals resulting in the generation of reactive oxygen species, ROS, which lead to the destruction of the cell walls of the bacteria [7], [8]. Recent studies were also performed on the effect Ag nanoparticles have on inhibiting the growth of bacteria in waste water biofilms [9], and on inhibiting bacterial growth when implemented in ceramic filters [10].

The projects in this paper address three areas in thermal-fluids where nanoparticles are implemented: electronics and heat exchanger cooling, solar distillation, and water purification.

\section{DESIGN OF A CLOSED-LOOP ELECTRONIC COOLING SYSTEM USING ALUMINA NANOFLUID (PROJECT 1)}

A closed loop cooling system was built by a group of undergraduate students in thermal-fluid design course to investigate the heat transfer performance associated with using a waterbased alumina nanofluid as a cooling medium in an electronic heat sink application. The experimental setup is shown in Fig. 1(a). Alumina nanofluid was prepared by mixing $20 \mathrm{~nm}$ alumina particles in deionized water for a concentration of $5 \%$ by mass ( $1.3 \%$ by volume). A digital geared-pump was used to pressurize the nanofluid for circulation in the closed-loop system. Two block-type heat exchangers were used: one to heat the nanofluid (HXR1), and another to cool it (HXR2). The interior of the block-type heat exchangers consisted of ten channels through which the nanofluid passes (Fig. 1(b)). HXR1 sat on top of a $500 \mathrm{~W}$ plate heater. A temperature controller was used to control the input heat to the base of HXR1. For HXR2, two cooling fans rated at $120 \mathrm{cfm}$ each were used to cool the top and bottom surfaces of this heat exchanger. Alumina nanofluid exiting HXR2 flowed into a reservoir tank in which a digital mixer with a top speed of 2,500 rpm was embedded. The reservoir tank fed directly into the pump inlet. Thermocouples were embedded at various locations to record the temperature variation throughout the system.

Heat transfer tests were carried out on the electronic heat sink system using the prepared deionized water-based alumina nanofluid. The results were compared to that of deionized water alone. The plate heater was set to a constant temperature of $91^{\circ} \mathrm{C}$, and the coolant flow rate was varied between 7.8 and $16.1 \mathrm{~cm}^{3} / \mathrm{s}$. Interface temperatures, and heat exchangers inlet

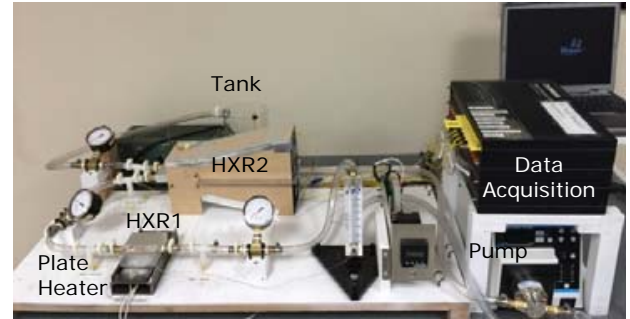

(a)

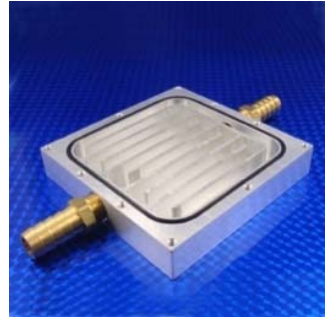

(b)

Figure 1: Closed-loop system components for (Project 1). (a) Experimental setup; (b) Block heat exchanger. 
water alone. The plate heater was set to a constant temperature of $91^{\circ} \mathrm{C}$, and the coolant flow rate was varied between 7.8 and $16.1 \mathrm{~cm}^{3} / \mathrm{s}$. Interface temperatures, and heat exchangers inlet and outlet temperatures were recorded once steady state temperature in the system was reached. The steady state temperature of the coolant associated with the different flow rates ranged from about 47 to $57^{\circ} \mathrm{C}$. The total volume of the coolant in the system was 2 litres. To minimize the precipitation of the nanoparticles in long duration tests, a stirring device that was embedded in the reservoir tank was turned on.

Thermal conductivity was conducted on the nanofluid using a KD2 Pro thermal properties analyzer by Decagon Devices. Tests revealed an enhancement in the thermal conductivity close to $4 \%$ for the $5 \%$ mass concentration of $\mathrm{Al}_{2} \mathrm{O}_{3}$. Rheological tests were also conducted on the nanofluid using a UL adapter attached to LVDVII+Pro viscometer. Suspensions were mixed thoroughly using a high-speed agitator for about 30 minutes before the viscosity tests were carried out. Tests were performed at an average temperature of $49^{\circ} \mathrm{C}$ for alumina in deionized water, and at $44.5^{\circ} \mathrm{C}$ for the deionized water. Fig. 2 shows the variation in the nanofluid and deionized water viscosity as function of the shear rate. The nanofluid is shown to behave as a shear thinning fluid.

The heat flux supplied by the electric heater at the base plate of HXR1, $q$ ", was determined from the temperature variation, $\Delta T$, across the plate wall thickness:

$$
q^{\prime \prime}=\lambda_{p} \frac{\Delta T}{\Delta x}
$$

where $\lambda_{p}$ is the thermal conductivity of the plate and $\Delta x$ is the plate thickness. The pumping power of the bulk fluid, $P_{\text {power }}$, was calculated from the volumetric flow rate, $\dot{V}$, and the pressure drop in the piping section, $\Delta P$ :

$$
P_{\text {power }}=\dot{V} \Delta P \text {. }
$$

Figs 3 and 4 show the wall heat flux (at the base of HXR1) and the heat transfer ratio as function of the bulk mass flow rate for the case of water-based alumina nanofluid and deionized water, respectively. An average increase of approximately $23 \%$ is seen in the wall heat flux for the case of water-based nanofluid compared to the case of deionized water.

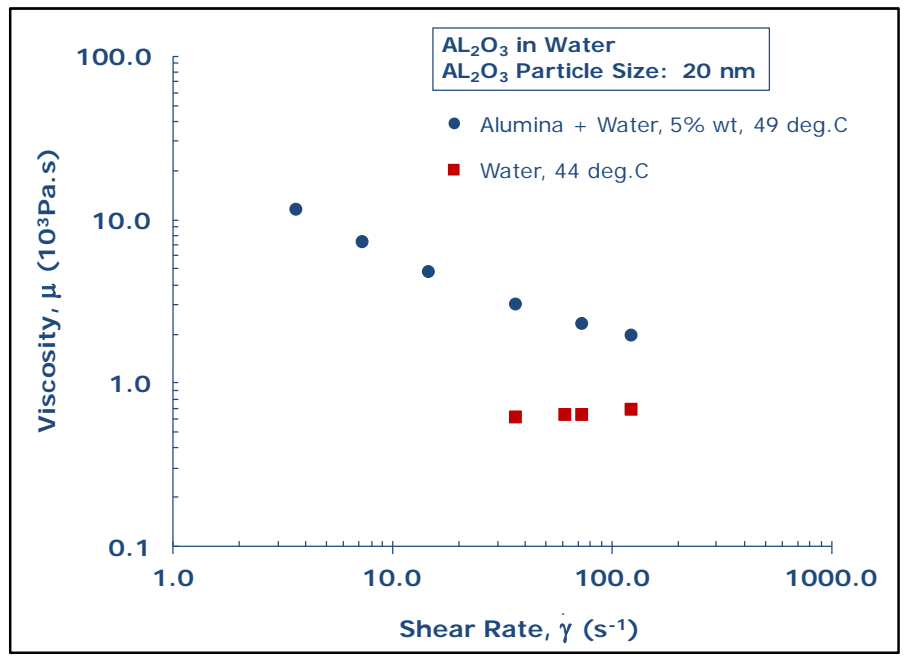

Figure 2: Viscosity versus mass flow rate. 


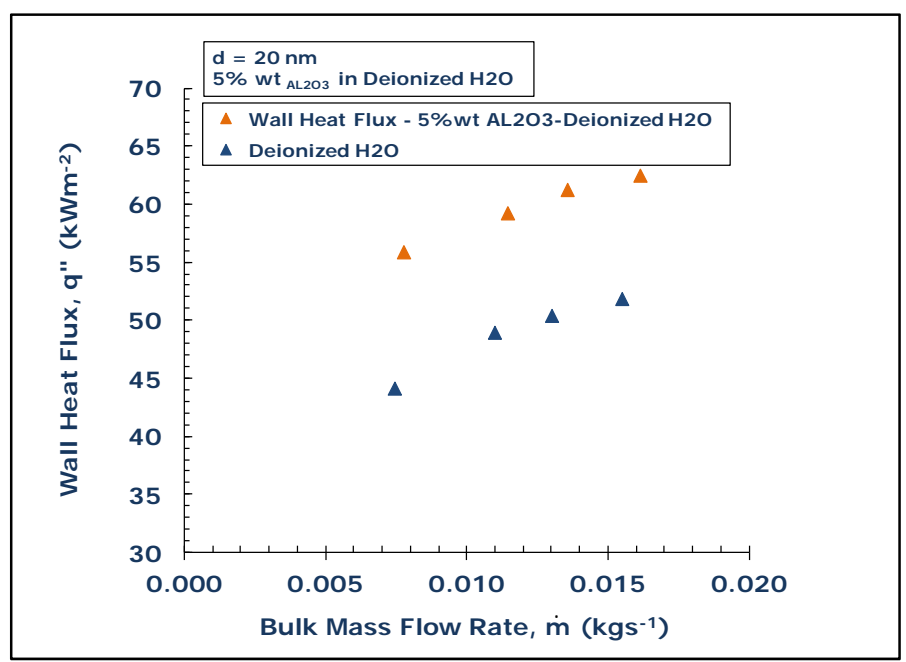

Figure 3: Wall heat flux versus mass flow rate.

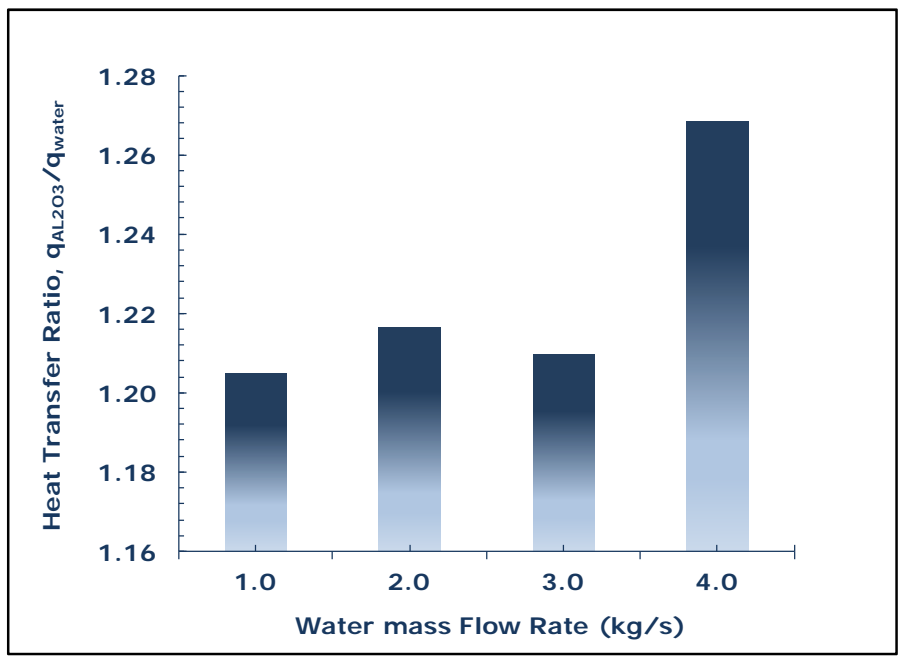

Figure 4: Heat transfer ratio versus mass flow rate.

Fig. 5 shows the pumping power as function of the bulk mass flow rate. The pumping power is shown to increase with mass flow rate and with the addition of nanoparticles to the base fluid. Compared to the base fluid, the nanofluid results in an average increase of up to $30 \%$ in pumping power.

While tests on the heat sink showed an average enhancement of $23 \%$ in the heat transfer rate, the $4 \%$ increase in the bulk thermal conductivity could not have been the only driving force behind this substantial increase in the heat transfer rate. It is possible that Brownian motion of the nanoparticles was behind this increase since the presence of nanoparticles can result in a reduction in the nanofluid thermal boundary layer thickness. 


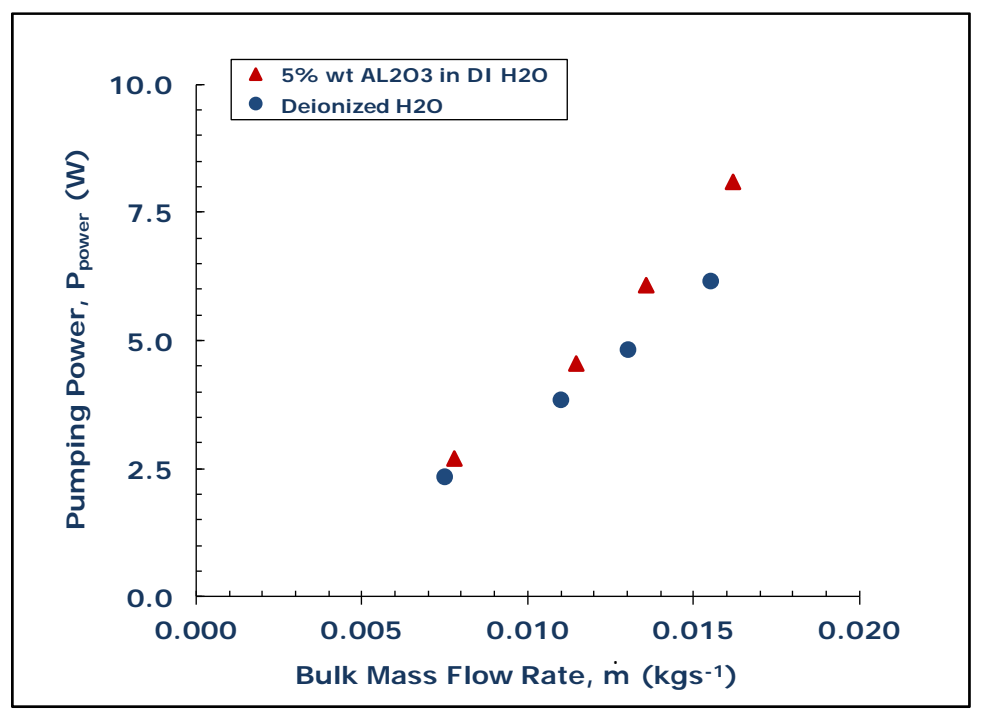

Figure 5: Pumping power versus mass flow rate.

\section{PERFORMANCE EVALUATION OF A RADIATOR-TYPE HEAT EXCHANGER USING ALUMINA NANOFLUID (PROJECT 2)}

In this project, a different group of undergraduate students also in the thermal-fluid design course constructed a closed-loop system to evaluate the performance of the radiator-type heat exchanger shown in Fig. 6. The heat exchanger (202 $\mathrm{mm}$ x $89 \mathrm{~mm}$ x $160 \mathrm{~mm}$ ) consisted of cross-flow finned-tubes having 10-passes with a single inlet and outlet. The tubes had an inner diameter of $7.73 \mathrm{~mm}$, an outer diameter of $9.5 \mathrm{~mm}$, and a length of $12.7 \mathrm{~cm}$. 80 fin plates $0.15 \mathrm{~mm}$ thick, $120 \mathrm{~mm}$ wide, and $38 \mathrm{~mm}$ deep were packaged normal to the tubes to form narrow passes of $1.4 \mathrm{~mm}$ average separation distance where air blowing from a fan can pass through (Fig. 6). A reservoir with a high-speed agitator thoroughly mixed the nanofluid, alumina with water using $50 \mathrm{~nm} \mathrm{AL}_{2} \mathrm{O}_{3}$ particles at a mass concentration of $3 \%(0.8 \%$ by volume), before it circulated through the system. A temperature controlled heating rod was installed in the tank to maintain the circulating fluid at a desired temperature before it entered the heat exchanger. The fluid was cooled using a blowing fan that was attached to one side of the heat exchanger. Thermocouples and flow sensors were installed throughout the system to monitor the fluid temperature and pressure.

Heat transfer tests were performed on the radiator-type heat exchanger. The performance of the heat exchanger using $50 \mathrm{~nm}$ alumina nanofluid as a circulating fluid was compared to that using distilled water only. Several test cases were conducted where the reservoir heater was set to different temperature settings ranging from $200-500^{\circ} \mathrm{C}$. Temperature data were recorded for about 45 minutes after the system reached steady state condition. Fig. 7 shows typical results for the temperature drop between the radiator inlet and outlet for the two types of the circulating fluids. As expected, the temperature drop is shown to increase with the decrease in the volumetric flow rate. The nanofluid is shown to outperform distilled water.

The radiator heat transfer effectiveness is defined as the ratio of the actual heat transfer to the maximum possible heat transfer that can be achieved. Fig. 8 shows a comparison in the heat transfer effectiveness between the two fluids. Tests conducted on the nanofluid showed an increase in heat transfer effectiveness reaching a substantial enhancement close to $49 \%$. 


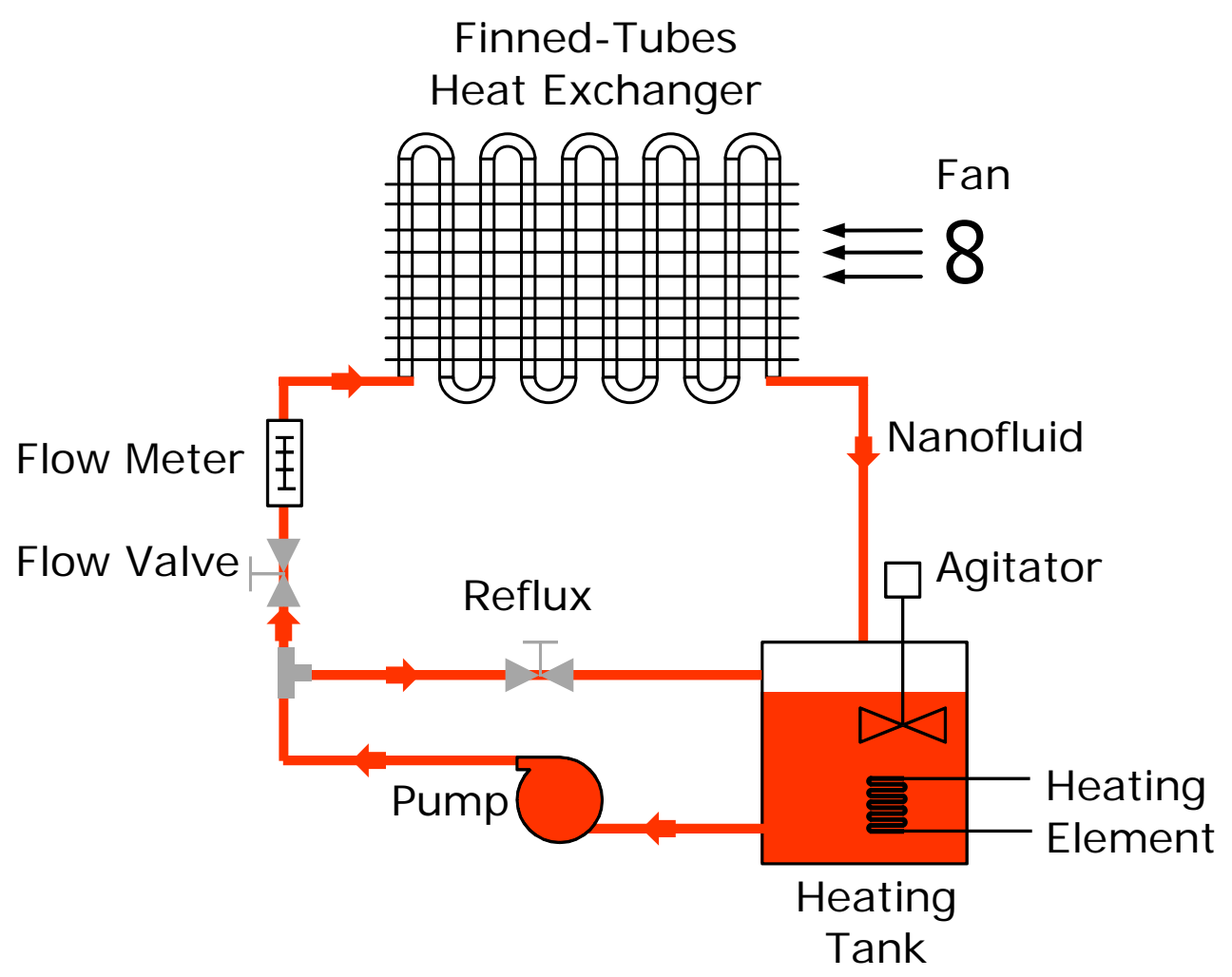

Figure 6: Experimental setup of a closed-loop radiator-type cooling system (Project 2).

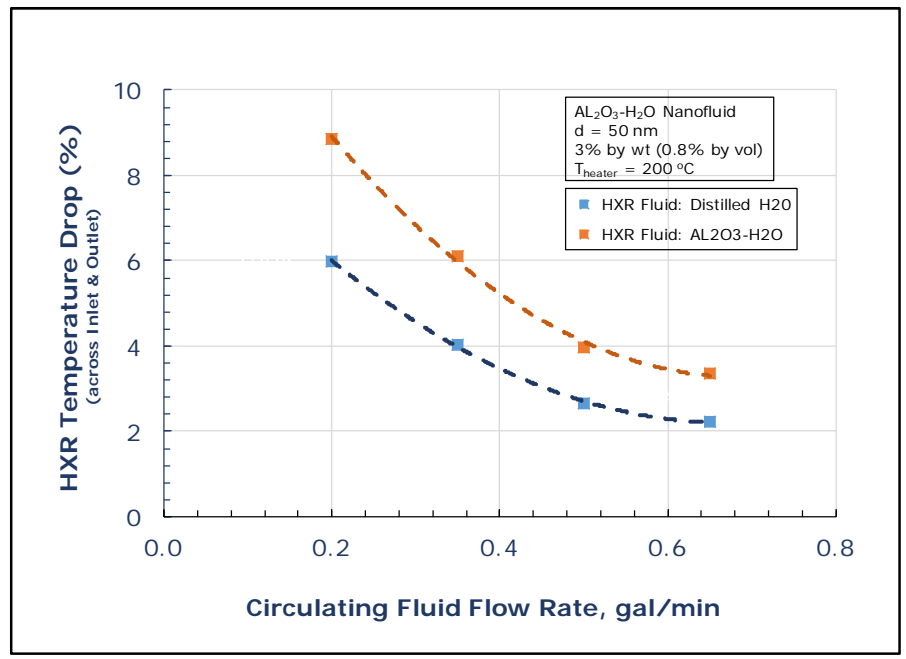

Figure 7: Comparison in radiator temperature drop using aluminium oxide nanofluid versus distilled water. 


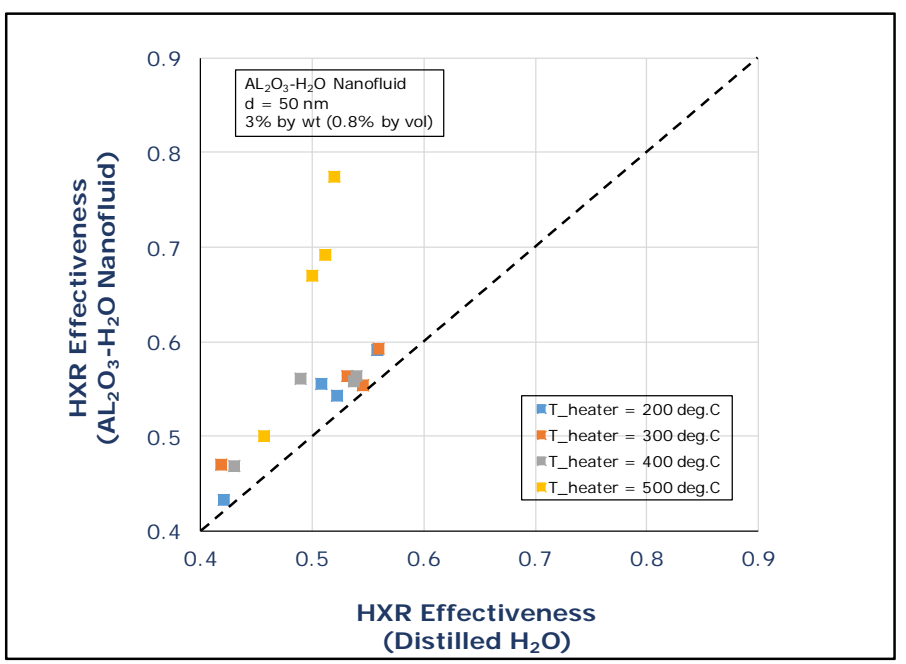

Figure 8: Comparison in radiator heat transfer effectiveness.

\section{EVALUATION OF THE ENERGY ABSORPTION BY ALUMINA NANOFLUID IN A SOLAR VACUUMED TUBE (PROJECT 3)}

The objective of this short experimental project was to investigate the effect $\mathrm{Al}_{2} \mathrm{O}_{3}$ nanoparticles have on altering the energy absorbed by a solar vacuumed tube when alumina was added to distilled water. Experiments were conducted to investigate the effect different $\mathrm{Al}_{2} \mathrm{O}_{3}$ nanoparticles concentrations and particle sizes have on the energy absorbed by the nanofluid. Alumina nanoparticles with an average diameter of 5 and $50 \mathrm{~nm}$ were tested. For solutions containing $50 \mathrm{~nm}$ particles, two concentrations of nanoparticles were prepared: $1,000 \mathrm{ppm}$ and $100,000 \mathrm{ppm}$, while for solutions containing $5 \mathrm{~nm}$ particles, nanoparticles concentrations of $100 \mathrm{ppm}$ and $10,000 \mathrm{ppm}$ were prepared. Fig. 9 shows the system experimental setup. The tube was inclined at $30^{\circ}$ with respect to the horizontal to receive the optimal solar radiation in Canyon, Texas. Thermocouples were embedded in the fluid to monitor the temperature at various locations, and in the air inside and outside the tube.

Figs 10 and 11 show the results of the study. For nanofluids using $50 \mathrm{~nm}$ particles, the higher the concentration of the nanoparticles (100,000 ppm compared to $1,000 \mathrm{ppm})$, the higher was the energy absorbed by the fluid. However, for nanofluids using $5 \mathrm{~nm}$ particles, the lower the concentration of the nanoparticles (100 ppm compared to $10,000 \mathrm{ppm})$, the higher was the energy absorbed by the nanofluid. The particle size and concentration appear to have a strong influence on the energy absorbed by the fluid.

\section{DESIGN OF A CLAY WATER FILTER IMPREGNATED WITH SILVER NANOPARTICLES FOR WATER PURIFICATION (PROJECT 4)}

The purpose of this project was to conduct a detailed performance study to design a low-cost clay filter system with anti-microbial protection capability for the purification of drinking water in developing countries. Fig. 12 shows a sketch of the experimental setup of the waterfiltering system, and Fig. 13 shows a sketch of a typical clay filter disk. Filters were made of clay material that was mixed with an appropriate amount of fine saw dust particle size. Five different types of clay powder material were tested: red art, off-white clay body, Hirondelle 


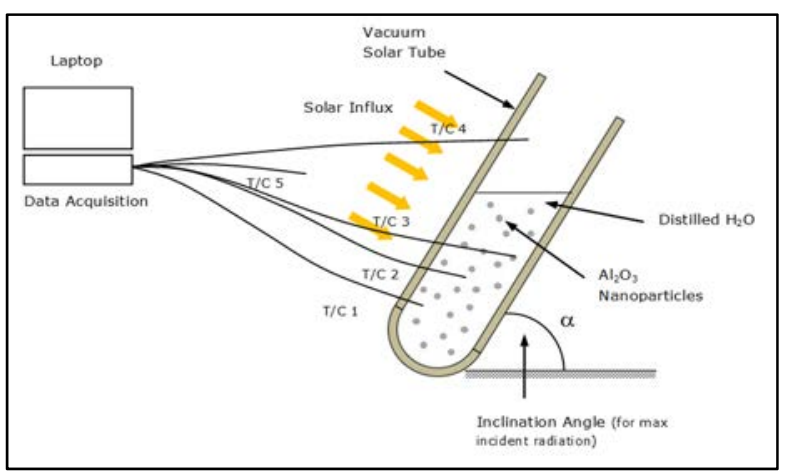

Figure 9: Experimental setup of a nanoparticle-based solar vacuumed tube (Project 3).

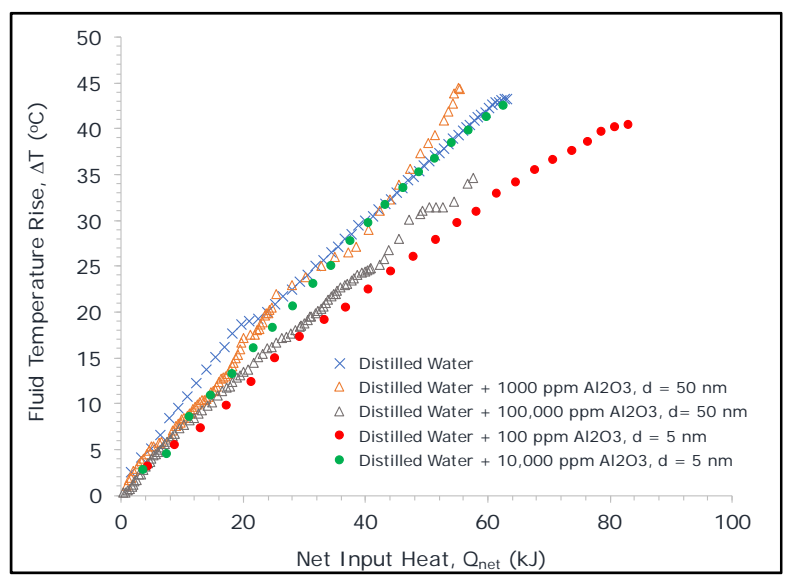

Figure 10: Fluid temperature rise versus net heat gain by the solar vacuumed tube.

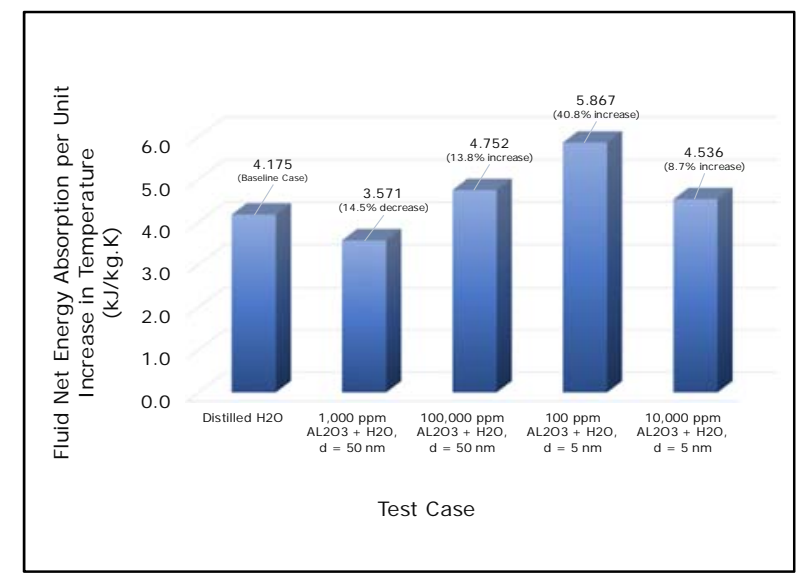

Figure 11: Nanofluid net energy absorption per unit increase in temperature. 


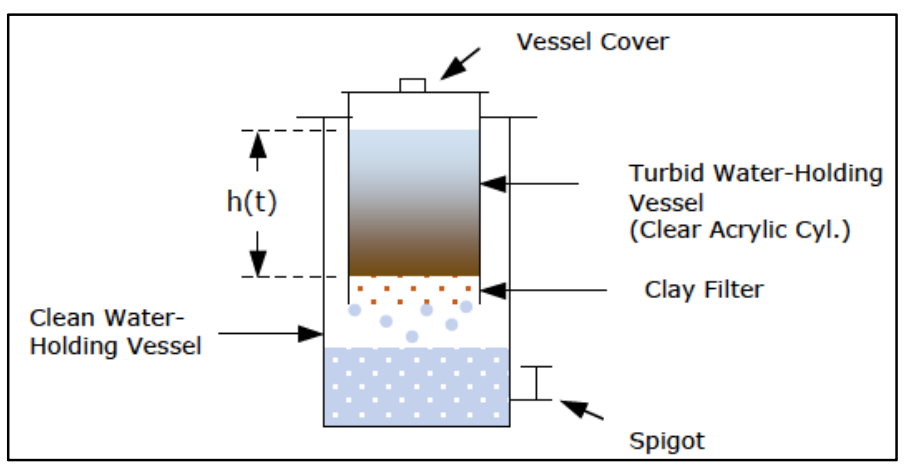

Figure 12: Experimental setup of the clay filter system (Project 4).

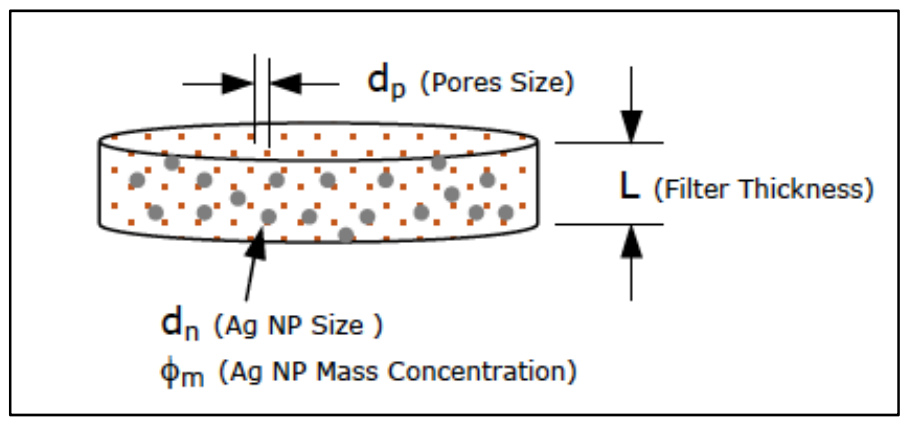

Figure 13: Sketch of a clay filter disk.

stoneware, Michael Simon stoneware no. 2, and Val Cushing off-white. Saw dust composition ranging from $22.5 \%$ to $30 \%$ by weight was also tested. Sieves of two sizes \#16 (1180 microns) and \#30 (600 microns) were used to strain the clay to a finer particle size. The clay-saw dust mixture was slowly fired in a kiln to a desired temperature of about $700^{\circ} \mathrm{C}$ in order for the dust particles to completely burn out and for the porous clay material to form. After arriving at the optimal condition to create the porous clay filter, filters without silver nanoparticles were initially formed. Filters with nanoparticles were later formed by impregnating the clay-saw dust mixture with silver nanoparticles before it was fired in the kiln. Silver nanoparticles were added to inhibit the growth of bacteria due to their anti-microbial properties. The filters were created in the shape of disks having a diameter of $7.62 \mathrm{~cm}$, and of three different thicknesses: $0.75,1.5$ and $2.25 \mathrm{~cm}$.

Filters were first tested for their flow resistance and turbidity effectiveness. Darcy's law for a gravity-driven flow through a porous media was experimentally implemented:

$$
\frac{k}{\mu} \frac{\Delta P}{L}=\frac{Q}{A},
$$

where $k$ is the permeability of the porous material, $\mu$ is the fluid viscosity, $L$ is the thickness of the porous material, $Q$ is the volumetric flow rate, $A$ is the filter cross-sectional area, and $\Delta P$ is the pressure drop across the porous material which is related to the time variable fluid height, $h(t)$ : 


$$
\Delta P=\rho g h(t),
$$

$\rho$ is water density, and $g$ is gravitational acceleration. The time response of the gravity-driven flow through the filter is that of a first order system that can be expressed by:

$$
h(t)=h_{o} e^{-t / A R_{L}^{\prime}}
$$

where $h_{o}$ is the initial height of the fluid column, $t$ is time, and $R_{L}^{\prime}$ is given by:

$$
R_{L}^{\prime}=\frac{R_{L}}{\rho g}
$$

where $R_{L}$ is the flow resistance.

Four different types of filters were created. Their parameters are presented in Table 1.

The four filters were analyzed for their flow characteristics. Turbid water was poured into the vessel above the filter disk as the sketch in Fig. 12 depicts. The results of the fluid tests are shown in Fig. 14. Fig. 14 shows the time response of the turbid water column height (above the disk filter). This data was then used to determine the filters flow resistance.

Fig. 15 shows the amount of clean water recovered from the four different filters in a 24-hour period test. The results show the collected volume to range from 4.2-5.8 litres. Turbidity tests were also performed on the recovered water (Fig. 16). Before the water was filtered, the turbidity of the water ranged from 850-950 NTU. Test results show the clay filters were very effective in considerably reducing the turbidity of water. For the four filters

Table 1: Parameters associated with analyzed clay filters.

\begin{tabular}{|c|c|c|c|c|}
\hline Filter No. & Material type & Sieve size & $\begin{array}{c}\text { Sawdust } \\
(\% \text { by wt })\end{array}$ & $\begin{array}{c}\text { Filter thickness } \\
(\mathrm{cm})\end{array}$ \\
\hline 1 & Off-white clay & No. 16 & 27.5 & 1.5 \\
\hline 2 & Off-white clay & No. 30 & 25 & 2.25 \\
\hline 3 & Val Cushing off-white & No. 16 & 22.5 & 0.75 \\
\hline 4 & Val Cushing off-white & No. 16 & 22.5 & 1.5 \\
\hline
\end{tabular}

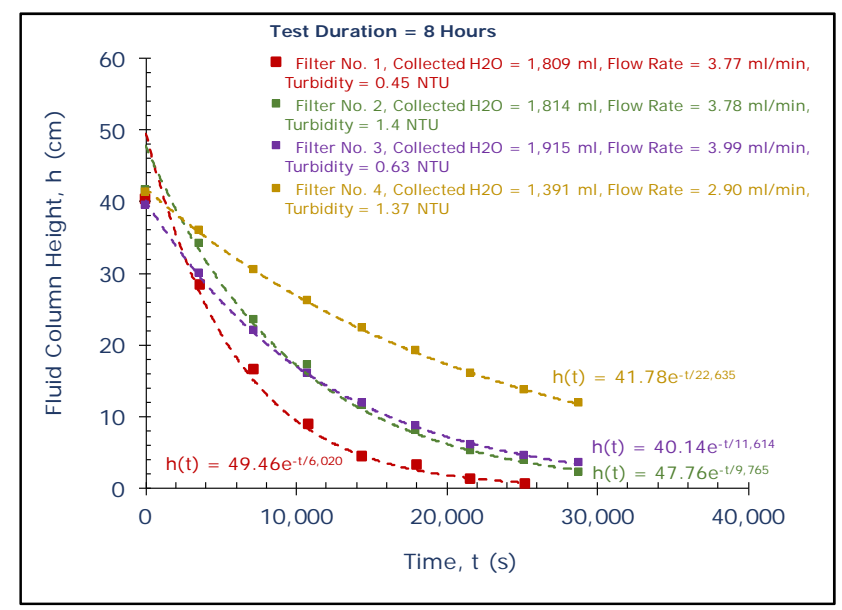

Figure 14: Tested filters transient flow response. 


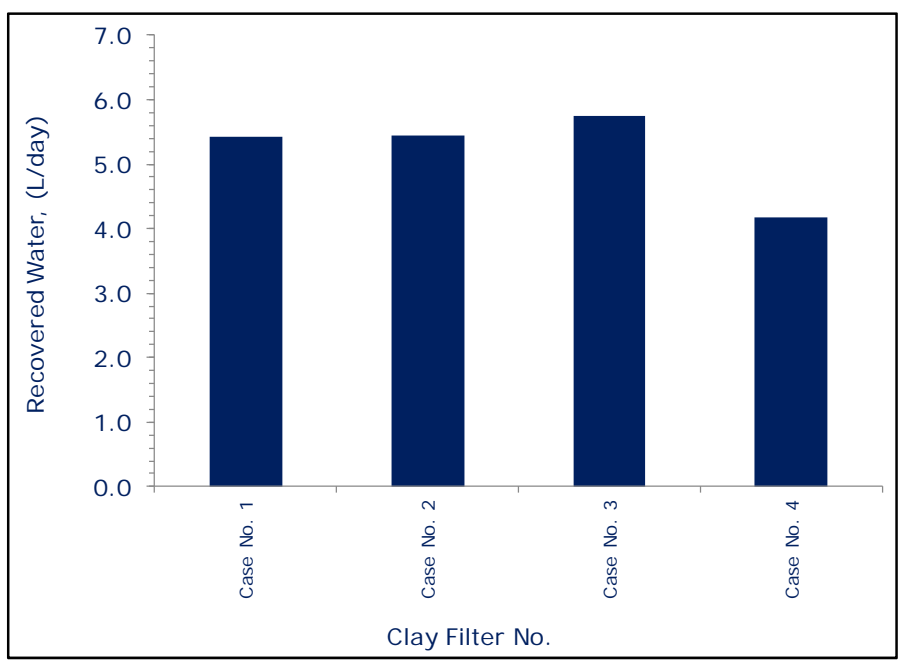

Figure 15: Recovered water from tested clay filters.

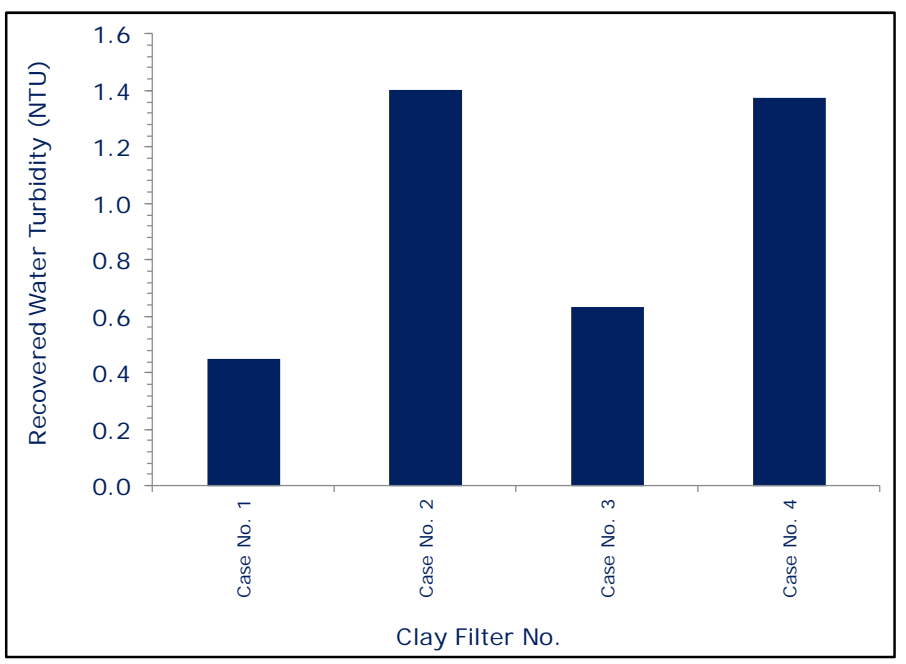

Figure 16: Turbidity tests on the recovered water.

that were analyzed, the turbidity of the recovered water ranged from $0.45-1.40 \mathrm{NTU}$, a level acceptable for drinking. Guidelines established by the World Health Organization on water state that the turbidity of drinking water should not exceed 5 NTU, and ideally should be lower than 1 NTU.

Two biological tests were performed. The first test was conducted on the 4 filters that did not have Ag nanoparticles. The water in the vessel above each clay filter was inoculated with E. coli bacteria for a concentration of $10^{4}$ cells $/ \mathrm{mL}$. Water samples from the collected filtered water was used to culture the bacteria cells on Petri dishes. Figs 17(a)-(d) show the growth of E. coli bacteria colonies. Although the bacteria colonies were far too numerous to count, 


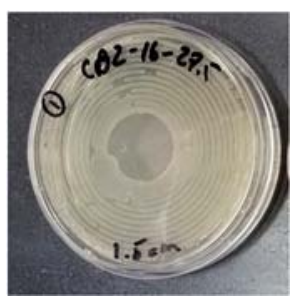

(a)

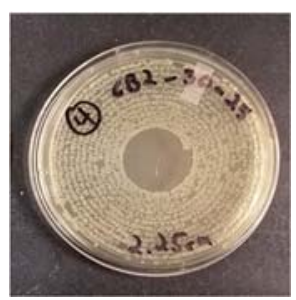

(b)

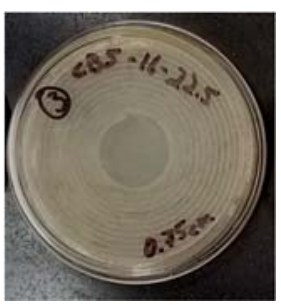

(c)

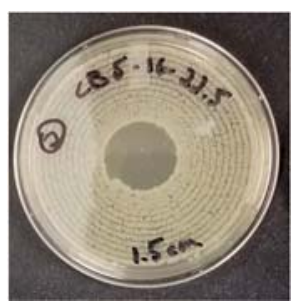

(d)

Figure 17: E. coli bacteria testing on inoculated water using filters without $\mathrm{Ag}$ nanoparticles. (a) Filter no. 1; (b) Filter no. 2; (c) Filter no. 3; and (d) Filter no. 4.

there was a notable difference among the filters. The thicker the clay filter the lower was the number of bacteria colonies observed. However, during the test it was speculated that some water may have leaked from the top water compartment into the lower compartment where filtered water was collected. In the second biological test, filters type 1 and 2 were impregnated with 5 grams of $\mathrm{Ag}$ nanoparticles each. In this case, the water in the top compartment was inoculated with E. coli bacteria for a concentration of $1.57 \times 10^{5}$ cells $/ \mathrm{mL}$. In a similar way, water sample from the collected filtered water was used to culture the bacteria cells on Petri dishes. However, no E. coli bacteria colonies were observed. The author believes that the biological tests done are not conclusive yet, and additional bacteria tests need to be carried out to validate the results and to investigate the effect several parameters such as the Ag nanoparticles concentration and filter thickness have on the presence of bacteria in the filtered water. These tests are under way at the time of the writing of the paper.

\section{CONCLUSION}

With the overcrowded mechanical engineering curriculum at West Texas A\&M University, it is possible to introduce nanotechnology research through undergraduate projects in existing courses such as thermal-fluid design and engineering research. Projects focusing on the use of nanofluids in electronic devices, heat exchanger systems, and solar vacuumed tubes were performed. Finally incorporating silver nanoparticles in clay filtering systems to provide antimicrobial protection capability for the purification of drinking water in developing countries was also undertaken and is currently under way. Feedback gathered from the students at the end of the projects revealed that the majority of the students had a clear understanding to the importance of nanotechnology and its practical application in our daily lives, and wanted more project opportunities similar to these to be provided not only in the thermal science courses but across the different areas in the mechanical engineering program.

\section{REFERENCES}

[1] Yu, W., France, D.M., Routbort, J.L. \& Choi, S.U.S., Review and comparison of nanofluid thermal conductivity and heat transfer enhancements. Heat Transfer Engineering, 29(5), pp. 432-460, 2008.

[2] Das, S.K., Choi, S.U.S. \& Patel, H.E., Heat transfer in nanofluids: A review. Heat Transfer Engineering, 27(10), pp. 3-19, 2006.

[3] Wong, V.W. \& De Leon, O., Applications of nanofluids: Current and future. Advances in Mechanical Engineering, 2010, pp. 1-11, 2010. 
[4] Selvakumar, P. \& Suresh, S., Convective performance of $\mathrm{CuO} /$ water nanofluid in an electronic heat sink. Experimental Thermal and Fluid Science, 40, pp. 57-63, 2012.

[5] Khedkar, R.S., Sonawane, S.S. \& Wasewar, K.L., Water to nanofluids heat transfer in concentric tube heat exchanger: Experimental study. Procedia Engineering, 51, pp. 318-323, 2013.

[6] Jin, H., Lin, G., Bai, L., Zeiny, A. \& Wen, D., Steam generation in a nanoparticlebased solar receiver. Nano Energy, 28, pp. 397-406, 2016.

[7] Mittelman, A.M., Lantagne, D.S., Rayner, J. \& Pennell, K.D., Silver dissolution and release from ceramic water filters. Environmental Science \& Technology, 49, pp. 8515-8522, 2015.

[8] Hajipour, M.J. et al., Antibacterial properties of nanoparticles. Trends in Biotechnology, 30(10), pp. 499-511, 2012.

[9] Sheng, Z., Van Nostrand, J.D., Zhou, J. \& Liu, Y., The effects of silver nanoparticles on intact wastewater biofilms. Frontiers in Microbiology, 6, pp. 1-11, 2015.

[10] Larimer, C., Effect of silver nanoparticle coatings on mycobacterial biofilm attachment and growth: Implications for ceramic water filters. Doctoral dissertation, University of Pittsburgh, 2013. 